\title{
The game of rankings in a quality world university space
}

\author{
Georgios Stamelos ${ }^{1}$ \\ Panagiota Evangelakou ${ }^{2}$
}

\section{ABSTRACT}

The objective of this text is to proceed to an analysis of international classifications and their impact on two levels: a] their unexpected public success, and b] their decisive influence on higher education policy and strategy. We argue that defining quality assurance is crucial in order to legitimize choices about evaluation on a political and institutional level. In any case, it seems clear that rankings are a dubious construction but highly legitimized by the public and governments. So, under these circumstances, rankings are here and they will probably stay, together with the financial issues they create. Indeed, rankings are an interesting new global market product which universities seem to have to negotiatewisely.

\section{KEY-WORDS}

Rankings. University. Higher Education Policy. Higher Education Governance. International Higher Education Competition.

\section{RESUMEN}

El objetivo de este texto es llevar a cabo un análisis de las clasificaciones internacionales y su impacto en dos niveles: a] su inesperado éxito público, y b] su influencia decisiva en las políticas y estrategias de educación superior. Sostenemos que la definición del aseguramiento de la calidad es crucial con el fin de legitimar las elecciones sobre la evaluación a nivel político e institucional. En cualquier caso, parece claro que los rankings son una construcción dudosa pero altamente legitimada por el público y los gobiernos. De modo que, ante tales circunstancias, los rankings están aquí y probablemente permanecerán, junto con las cuestiones financieras que generan. De hecho, los rankings son un nuevo producto de mercado global que las universidades al parecer tienen que negociar de manera sabia.

\section{PALABRAS CLAVE}

Rankings. Universidad. Políticas de Educación Superior. Gobernanza de Educación Superior. Educación Superior internacional. Competición.

\footnotetext{
$1 \quad$ Univerisity of Patras, Greece. gstam@otenet.gr

$2 \quad$ Univerisity of Patras, Greece. penny-Ifpr@hotmail.com
} 


\section{INTRODUCTION}

Rankings made their appearance more than 10 years ago now as an experiment, or a game. The interesting thing is that beyond their obvious weaknesses they conquered not only the national governments, who now use them in the shaping of their policies, but also - and more importantly the wider public. What is impressive is that the rankings no longer determine only the institutions' strategies and the governments' educational policies, but immigration policy too! Consequently, it appears that rankings are here to stay and what one has to understand is the need for them to stay despite the evident inadequacies and problems (Rauhvargers 2011, 2013). It will then be necessary to investigate the universities' attitude towards the rankings. To do this though, first the essence of the chief rankings needs to be analysed, and then the effect on the universities themselves has to be investigated.

\section{PRESENTATION OF THE MAIN RANKINGS}

The total number of world universities is estimated at 18,000 - 24,000, the performance of which can be measured by the rankings. The five most recognized ranking mechanisms, with each using its own methodology, are: 1. Academic Rankingof World Universities, 2. World University Rankings, 3. QS World University Rankings, 4. Best Global Universities, 5. Webometrics Ranking of World Universities.

Below, we will present the criteria and indicators used by the aforementioned rankings.

\section{Academic Ranking of World Universities [ARWU - Shanghai]}

In Academic Ranking of World Universities,500 universities are selected and ranked,based on two criteria. First, the candidate university should either be a sport university or have sportrelated units, and second, the institution should have been actively engaging in research in the past five years.

More precisely, universities are ranked by several indicators of academic or research performance, including papers indexed on the Web on "Nature" and "Science" [20\%], the number of citations to papers published by an institution [20\%], citations per paper [25\%], papers published in top 25\% journals [25\%] and percentage of an institution's internationally collaborated papers [10\%]. For each indicator, the highest scoring institution is assigned a score of 100, and other institutions are calculated as a percentage of the top score. Scores for each indicator are weighted to arrive at a final overall score for an institution. The highest scoring institution is assigned a score of 100 and other institutions are calculated as a percentage of the top score. It is important to mention that an institution's rank reflects the number of institutions that sit above it.

\section{World University Rankings by Times Higher Education [THE]}

The Times Higher Education World University Rankings judge research-intensive universities using 13 carefully calibrated performance indicators to provide the most comprehensive and balanced comparisons, trusted by students, academics, university leaders, industry and governments.

To be more specific, the performance indicators are grouped into five areas: teaching the learning 
environment [30\%] - including reputation survey on teaching [15\%], research [volume, income and reputation] [30\%] - including reputation survey on research [18\%], citations [research influence] [30\%], international outlook [staff, students, research] [7.5\%], industry income [knowledge transfer] [2.5\%].

\section{QS World University Rankings}

The QS World University Rankings use six metrics in order to evaluate universities' performance, which are: academic reputation [40\%], employer reputation [10\%], faculty/student ratio [20\%], citations per faculty [20\%], international faculty ratio [5\%] and international student ratio [5\%].

\section{Best Global Universities [BGU]}

The U.S. News Best Global Universities rankings were produced to provide insight into how universities compare globally and focus specifically on schools' academic research and reputation overall, using the following indicators: global research reputation [12.5\%], regional research reputation [12.5\%], publications [10\%], books [2.5\%], conferences [2.5\%], normalized citation impact [10\%], total citations [7.5\%], number of highly [10\%] cited papers [12.5\%], percentage of highly [10\%] cited papers [10\%], international collaboration [5\%], number of top [1\%] cited papers [5\%], percentage of top [1\%] cited papers [5\%].

\section{Webometrics [WEB]}

The Webometrics or Ranking Webis the largestacademic ranking of HigherEducation Institutions. Since 2004, the Webometrics Ranking has been published twice a year [data is collected during the first weeks of January and July and made public at the end of both months], covering more than 27,000 Higher Education Institutions worldwide, in order to provide information about their performance based on their web presence and impact.

According to the Webometrics Ranking, its original aim is to promote academic web presence, supporting the Open Access initiatives for significantly increasing the transfer of the scientific and cultural knowledge generated by the universities to the whole of Society. For this reason, the objective is not to evaluate websites, their design or usability or the popularity of their contents according to the number of visits or visitors.

Web indicators are considered as proxies in the evaluation of the university'sglobal performance, taking into account its activities and outputs and their relevance and impact. More specifically, the current methodology uses the following indicators: Visibility, which refers to the number of external networks originating backlinks to the institution's webpages [50\%], excellence or scholar that describes the number of papers amongst the top 10\% most cited in 26 disciplines [35\%], transparency or openness according to the number of citations from Top authors [10\%] and $5 \%$ presence, which includes the size [number of webpages] of the institution's main web domain and the subdomains that share the same [central or main] web domain and all the file types including rich files like pdf documents.

As becomes obvious, each ranking makes use of different criteria in different quotas, and these criteria can change during the year, sometimes every year. In addition, while some rankings are linked to companies, it is not unusual for consortia to break up, to reform or to disintegrate permanently. 


\section{Unexpected success}

The rankings were unexpectedly popular. The reason is perhaps that they are simple for the non-expert reader and easily digestible and consequently, they appeal to the archetypal average consumer. In other words, the rankings have persuaded us that the common man can easily and quickly find, either out of direct interest or simple curiosity, the best institutions in his country, or on the planet, through the measuring of their performance.

Obviously, their promotion through the mass media was and continues to be important. Whether it is now the media who shape the climate or whether it is the needs of the public or even both of these together, is a matter which we will not trouble ourselves with in this text. It is the result we care about: the common interest ofboth the media and the public.

A more complicatedmatter is theirwide acceptance and use by the governments. And if in countries like the USA the rankings are not as new an invention as they are for the rest of the world, for Europe this widespread acceptance is perhaps striking.

Of course, the environment and the wider conditions hadalready been shaped: promotion of international competition, the formation of a hyper-national space of higher education, the need for transparency, comparability, evaluation with common criteria, pressure for changes, see complete turnarounds, even in the vision and mission of the university, and so on. The supposed measure of performance facilitated the governments in documenting divergences and noting their universities' inadequacies, so at the same time establishing the need for interventions and changes. Consequently the rankings functioned as a mechanism for deregulation of the universities and legitimization of government initiatives for new regulations of the university space. If now the question is how they managed to do this, the answer seems to be based in the developing social dislike for the university institution to the extent that it could no longer guarantee social status and/or job prospects for its graduates. The two pillars, in other words, upon which its social image and acceptance were built [Stamelos, 2014].

From the point of view of the users, the rankings have, on the one hand, a relationship with the massification of university studies, and on the other, with the view of studies first and foremost, if not exclusively, asleading to employment. From the moment then that the chief or at least the most important expectation of study is for professional prospects, failure to achieve this objective can be seen as a failure of the university itself.

The ensuing increasing social intolerance leads to the legitimized demand for greater transparency and social accountability. In any case, the institution of the university, as a part of the space of life-long learning, is particularly vulnerable to change, as much in terms of its growth as in terms of the cost of its operation. Hence, its supervision becomes a major issue for the central political scene, for both the government's social policy, and for its economic policy.

\section{The discussion on quality assurance as a guarantee}

The discussion surrounding 'quality' is housed precisely in this need for the supervision of the rapidly expanding body called university. Evaluation has proved to be a quality assurance tool. This discussion has become a central issuein international consultation on the university, and the relevant literature is extremely rich. 
Within the framework of the European Union, thisinterest seems to have begun with the Memorandum on tertiary education in the European Community in 1991. It is worth noting that the concept of quality was no more than a horizontal axis (page 18) in the text in question, which had a great influence at that time. Since then, things have changed drastically, especially with the onset of the creation of the European Higher Education Area, where quality assurance is highlighted as a central reference point.

Despite that, there is no commonly accepted definition of quality. In fact, there are international bodies, such as OECD which state that they are not interested in the term [Bartzakli, 2011]. Indicatively, a paper with a significant impact in the specialised literature is that by Harvey and Green (1993) in which the writers, attempting to analyse quality, divide it into four types: a] quality as excellence, b] quality as fitness for purpose, c] quality as value for money and d) quality as transformation.

One can observe then that quality is defined in terms of different objectives. In the first case, [excellence) quality is understood as a process for the pinpointing of the first or at least the best. In the second case, quality is linked to the ability of an institution to set targets and implement them. In the third case, quality is understood as efficiency, in other words as the relationship between cost and result. Finally, in the fourth case, it is assigned the meaning of the ability to transform.

It is evident that the first case [excellence] is consistent with the view of quality as a ranking indicator. The logic of rankings is founded on this version. However another differentiation seems to us more important. The version of excellence presupposes a view of the institutions as isolated units, which compete with each other to be first [excellence]. In all the other cases, the view, while focussing on each institution, doesn't marginalize, from the outset, the consideration of the whole of the institutions in a country as a single system. The logic then of the rankings, that is to say, of excellence, in essence pushes the institutions, as isolated structures, into competition with each other, the prize for which is individual distinction which is not interested in and in any case neglects the importance of the quality assurance of a system [for example, of a country's higher education institutions]. It is a different perspective which seems to have its roots in the American view of things and which destabilizes the European traditions of national states which are built on the idea of national education, understood as a system ${ }^{3}$.

3 The most interesting and structured European example concerns the United Kingdom. In contrast with the American model, it invests in the reputation of its system [indeed putting to one side its two most reputed universities, Oxford and Cambridge] and using its globalised language as a vehicle, develops structured and systematic policies for the attraction of foreign students, envisaging its higher education system as an export heavy industry from a neo-liberal perspective which is especially efficient and economically effective for the country. In fact the applied policy is of such intensity but closely supervised that, for example, based on international trends and the dynamic of the attraction of foreign students, the British government plans, in the coming years, to establish three new universities to cope with the needs of international demand.

A second example could be that of Holland, which from the same systemic viewpoint, and with the adoption of English as the language of teaching, attempts to compete with the United Kingdom, offering the same quality [reputation] at more affordable prices. The result appears to justify the endeavour.

Of course, it should be noted that in recent years both these countries are being shaken by student protests over the existing high fees.

[http://www.theguardian.com/higher-education-network/2015/mar/25/university-protests-around-the-world-a-fight-againstcommercialisation

http:/ / www.universityworldnews.com/article.php?story=20150331053421218

http:/ / www.universityworldnews.com/article.php?story=20150415052244352

http:/ / www.dutchnews.nl/news/archives/2015/04/amsterdam-university-chief-quits-over-student-protests/ http:/ / www.timeshighereducation.co.uk/news/students-occupy-buildings-at-london-universities/2019350.article http://www.timeshighereducation.co.uk/news/tuition-fees-hike-hit-courses-with-low-salary-expectations-study/2019501. article]. 
This, on the other hand, does not mean that in the national states there are no institutions of different speeds, prestige and repute [there are] or that higher education doesn't reflect the social inequalities that exist within its framework. The turnaround that the discussion on rankings recommends lies in the individualising of the institutions and the shaping of conditions of intense competition between them, moving the interest from the system to isolated structures.

\section{The problems of the rankings}

The rankings persist in the view that in a simple way [the determination of 4-5 indicators] they can check the performance of all the institutions in the world [or one country] and rank them in a valid and reliable way.

Interest lies in the fact that on the one hand, obviously, institutions that are different in size, targets and content appear to be compared as if they were similar, violating fundamental principles of mathematics [Nylander and others 2013), and on the other, detachment of the institutions from the context and their comparison (with the same criteria) clearly violates the general assumption that prevailed after the second world war and according to which education is directly linked to the economic growth of a country. It is interesting that one of the most significant international bodies, the OECD,was created based on this assumed relationship. This relationship has also been highlighted in publications by the Greek network Higher Education Network [HepNet], which compares the results of the Greek higher education institutions on webometrics with the corresponding countries in Europe with the same GNP [HepNet 2013, 2014].

Focusing on the measurement indicators, it is important for one to investigate:

a. What is claimed to be measured in relation to what is actually measured

b. The way in which the results are measured and what they mean.

The EUA has published a series of such analyses with particularly insightful documentation [Rauhvargers 2011, 2013]. Here we should note only that those responsible for the 5-6 most well-known rankings seem to be aware of the problem and each year they reshape either the content of the indicators or the weight coefficient for each indicator. This reveals, on the one hand, that they themselves are not satisfied, and on the other, that simultaneous and/or continuing comparisons are scientifically weak in the sense that the data [criteria and/or weight] are continually being modified. In fact, one major feature of the providers of the rankings in question is the superficial description of their methods and the poverty of their indicators. In any case, and perhaps what is most impressive, is that the non-consistent manner in which the data are used obstructsneither the use nor the popularity of the rankings.

Other findings have to do with a series of gaps or distortions in the suggested rankings [Rauhvargers 2011, 2013). For example:

a. The focus on an elite, ignoring the thousands of institutions around the world and their millions of students.

b. The overemphasis on research and research activities with the parallel silence surrounding the quality of teaching and learning. In fact, sometimes there is a very characteristic shift 
according to which the quality of teaching and learning can be measured with the Nobel prizes of an institution's previous students!

c. The acuteover-determination of English at the expense of other languages.

On the other hand, the number of rankings is continually increasing and there are more and more specialised ones too. What's more, there are not only global ones, but by wider geographical region too, or even by state. We also have rankings by scientific area or by institution according to its age (year of founding], or again by policy axes [e.g. internationalization] where it is recommended that the label of internationalised university is awarded (the case of the Quality Assurance Agency in Holland - Flanders).

Realization of the inadequacies of the first generation of rankings [despite their social acceptance) provided the impetus for the creation of a new generation of rankings, which appears to want to develop the rudimentary initial rankings further, recognising their problems. Such cases are the U-Multirank and the AHELO. The U-Multirank claims that it is the European answer to the simplistic first generation rankings. Its conception is interesting because it overturns many of the principles of the rankings (Van Vught and Ziegele 2011). For a start, it doesn't propose a final ranking. Next, it wants to be founded on the interaction of different categories of interest groups [e.g. students, families, teachers, researchers, institutions, professional bodies and so on]. Hence, it leaves the interested parties to choose from a series of different proposed variables those which actually interest them, recommending a comparison of the chosen institutions, without ranking. In this way, someone who is searching for undergraduate studies can use some of the proposed variables [e.g. student life, support, professor-student ratio, graduation percentage, etc], in contrast to someone who is searching for doctoral studies and who would be more interested for example in the scope and quality of research, collaboration with the workplace or large companies and so on. At the other extreme, an employer would be interested in other variables depending on whether he was searching for a graduate of the first or third cycle. Hence, it is the user who, defining the variable arrives at a comparative table with the institutions in the countries he has determined and which interest him. It is interesting that at its presentation in Athens in 2014, during the Greek presidency, the criticism that was levelled at it, especially from non-European specialists, was that it is extremely complex and needed specialised knowledge and that is why its failure was predicted ${ }^{4}$.

As far as the AHELO of the OECD is concerned, here focus is on the learning outcomes and attention is centred on student centred learning and on research on teaching-learning processes. AHELO uses the Tuning method for the development of its tools, separating the skills into the generic and the subject specific, implementing pilot global research in economics and engineering (Tremblay, Lalancette and Roseveare 2012, OECD 2013a, 2013b). In addition, it is directed at three different groups of interested parties, students, professors and employers. What is interesting about the attempt by AHELO is that it distances itself from the classic rankings, constructing a full, extensive and specialised questionnaire which checks only learning outcomes ${ }^{5}$. Hence it essentially accepts the position that it is not possible for someone to rank all the institutions on the planet based on 4-5 indicators ${ }^{6}$.

\footnotetext{
$4 \quad$ personal testimony of one of the writers who attended the event.

5 AHELO stopped two years ago as it failed, but OECD continues its effortsin a different direction.

6 Another ranking, which diverges from the general assumptions for the formation of rankings is the Universitas 21 which, in contrast to all the others, does not rank institutions but systems [http://www.universitas?1.com].
} 


\section{The reaction of the universities}

Let's begin from the end. Reproducing the EUA's finding [Rauhvargers 2013) the chief danger is for a university to take the existing rankings too seriously! On the other hand, it is by now clear that the impact of the rankings is becoming more and more complex and decisive for an institution to the extent that it influences its reputation, in other words, the flow of students into it, as well as the interest of sound businesses for collaborations, and the attraction of better professors. In any case it has a significant effect on its finances. The rankings also effect the way an institution operates since their increasing numberand specialization create multiple needs for the collection of data which are different each time, consequently creating a bulk of bureaucratic work that is getting heavier and heavier.

Of course, on the other hand, it is becoming ever more important for an institution to be transparent and accessible to its users and to consider, through its internal mechanisms, how it can continue to improve. What's more, and for reasonswhich first and foremost concern its own protection, it should consider improving the rankings themselves, pushing for themto be reshaped beyond the initial early attempts. In any case, it would be good for the higher institutions to realize that whether they like it or not, the rankings are here to stay and will continue to have an influence on them as much in terms of the policy decisions made by the authorities, as in terms of the reactions of the users and the wider public.

On the other hand, it would be risky for an institution to shift attention from the improvement of its quality to improvement of its position in the rankings. The latter could lead to critical decisions that would diverge from the standards of quality assurance. For example, an institution could consider limiting appointmentsfor teaching staff, aggravating indicators such as teachers per students, purely to be able to find the necessary funds to invite one or more Nobel award holders to give lectures. Certainly doing so would improve its position in some rankings but it is by no means certain that it would improve the quality of the institution.

One more example could concern the behavior of a government. In its attempt to show off its 'national champion' it might limit the budget for all the institutions in the country except for the one to which it would transfer all the funding. In this way it is likely that it would create a champion, but it would certainly also create problems for the other institutions. This logic of 'excellence' is not in itself a problem, but it is a significant problem in the context of a systematic approach.

In any case, it seems that uncritical use of the rankings by the universities poses a danger. Hazelkorn [2013], leveling especial criticismat the rankings and troubled by the universities' reaction, attempts to demarcate the matter as follows:

\section{DON'T}

-Change evaluation process or criteria to conform to rankings;

-Use rankings as a stand-alone evaluation tool;

-Use rankings or indicators uncritically to inform final decisions;

-Manipulate data in order to present a better outcome. 
DO:

-Remember choice of indicators is always subjective;

-Use rankings only as part of overall QA, assessment or benchmarking;

-Consider value and relevance of other transparency instruments;

-Align evaluation process with the goals, objectives and priorities;

•Ensure evaluation teams and HEls understand limitations of rankings.

\section{The case of the Greek universities}

The reaction of the Greek universities to the rankings would perhaps be interesting, as a case study. Initially there was a strong reaction which was founded on two points: a] no Greek university appeared in the top 100 while only two [2] appeared in the Shanghai list (the University of Athens and the University of Thessaloniki] ${ }^{7}$, b] the governments of the time used this picture to accuse the universities of inadequacies and a general crisis and to promote radical changes [e.g. Law 4009/2011). Later on however, through specialized publications [HepNet, 2013, 2014, 2016] and using Webometrics which in contrast to all the others ranks all the institutions on the planet,they realized that for one to occupy for example a position in the top 600 universities in the world places an institution in the top 2-3\% of the world. This, from one perspective, places this institution in a global elite, which doesn't bear out the governments' objections. From there,there emerged a questioning of the significance of being an institution in the top 100.

This development gave the Greek universities some self-confidence and they then began to play the game of the rankings, without being concerned over not appearing in the top 100. So, all the more often announcements appearin the press from the universities with their position in various rankings [that the universities communicate this data to the press is not at all accidental). Of course, not all the institutions do this. There are 6-8 that seem to have their sights set abroad and which appear to be shaping a special group, which is expected in time to become aware of its distinctiveness.

As an example, the University of Patras could be mentioned. It has already set up an internal structure, which is occupied with the rankings and has chosen to give priority to Multirank and QS without neglecting the others. In its most recent publication [May 2018] it sets out its position:

Multirank: a] 13 of the institution's 24 Departments have been included, b) in four indicators, as against three last year, the university was evaluated with ' 1 ' (in the sections of 'research' and 'knowledge transfer'].

QS World University Ranking: a] a stable position in relation to last year, in positions 701-750, b) in the category of citations per faculty the university's grade is 38.1 while the average for the evaluated universities is 34.1, c] seven Departments in the global elite [Medicine, Chemistry,

$7 \quad$ Not by chance, since Shanghai in reality measures the quantitative size of an institution. 
Civil Engineering, Mechanical Engineering and Aeronautics, Chemical Engineering, Electrical and Computer Engineering and Department of Computer Engineering and Informatics].

Times Higher Education World University Rankings [THE]: a] stable position between 601-800, b) for universities founded between 1945 and 1967, in positions 101-150, c] in two fields in a position of excellence [Engineering and Technology and in the sub-unit Biological Sciences in the field 'Life Sciences'.

Webometrics: $486^{\text {th }}$ position or in the $1.8 \%$ of the best in the world[an improvement on last year's position of $541^{\text {st }}$.

CWTS Leiden Ranking: 585 ${ }^{\text {th }}$ position on a global level and 206 on a European one.

RUR [Round University Ranking]: 693 ${ }^{\text {rd }}$ position, Medicine at 364.

National Taiwan University [NTU] - Performance Ranking of Scientific Papers: a] the University of Patras is to be found in positions 501-600, and b] in eight thematic areas it is in a high position, with the best being: Chemical Engineering [179], Mechanical Engineering [253] and Material Sciences [280].

Academic Ranking of World Universities [ARWU] [Shanghai Ranking]: the third Greek university to be included in the position of 500+.

The analytical comparison shows, on the one hand, the keenness of the university to publish what it considers to promote it, and, on the other, it reveals, firstly, the specialization and secondly the use of the rankings in such a way as to show off the institution's successes.

In any case, what is highlighted is that a university devotes a part of its activity and staff to feed the various rankings with data, sometimes paying subscriptions, following the publications of the rankings and then diffusing the results to society in various ways. In addition, something which isn't manifest, but is implied, is that Departments and curricula that don't appear in the rankings (and usually they are from the Social and Human Sciences] are considered a burden and seen to 'spoil' the university's results. The next step could be their marginalization or even their discontinuation in the name of 'improvement' of the institution's overall position in the rankings.

\section{The contemporary stakes: rankings or quality assurance?}

Hazelkorn, attempting to outline the stakes, claims that the whole question in based on globalization and the role of higher education in it. The rankings as much as quality assurance [evaluation] are trying to respond to it in various ways. And indeed the discussion surrounding a world university system is ongoing [Lenzen, 2015]. Based on globalization then, the discussion on higher education and its quality is linked:

a) On a national level

A1] with geopolitical games as well as national pride,

A2] with the view of quality as a mechanism for the attraction/maintenance of people, which is related to investments, work places and the highlighting of talent, 
A3) value for money and return on [public] investment [consequently as an industrial activity and for some countries as a sector of their heavy industry],

b) On an institutional level

B1] with institutional reputation and prestige,

B2) with the recognition of its scientific research,

B3] with participation in international networks,

c) On an individual level

C1] with the graduates' employment prospects

C2] with career opportunities and life-style [Hazelkorn 2013].

If one focuses on the institutional level, the discussion today on rankings and quality assurance [evaluation] hides a powerful stake, more political and less scientific, the outcome of which however will influence higher education in the future.

Indeed, in Europe, but gradually too in more or less the whole world, national Quality Assurance Authorities were established. In fact, in the context of the European coordination for the creation of the European Higher Education Area, [EHEA] a more or less common system of evaluation was developed which is overseen by the ENQA [European Network of Quality Assurance). This system is coordinated on a European level in terms of its targets, the object of evaluation and its form. Its target refers to the type of evaluation (for improvement or for accreditation]. The object of evaluation may be institutional evaluation [institution and/or curriculum, etc] and the evaluation of each Authority by ENQA [audit]. The form concerns its frequency, as well as dual internal and external evaluation where the external is based on the findings of the internal. What one should note is that this system of evaluation is connected horizontally with three of the four versions of quality according to Harvey and Green [fitness for purpose, value for money, transformation] but not with the version of excellence. This reminds us of the logic of the rankings. Consequently, here two different approaches are being outlined, one according to the logic of the rankings and one according to the logic of quality [Hazelkorn 2013).

As almost all the states acquired national quality assurance Authorities, they noted, at about the end of the first decade of the $21^{\text {st }}$ century, that this mechanism and the whole system they had adopted, was expensive. The tariff established on an international level for the evaluation of institutions [EUA] and National Authorities [ENQA] is indicative, and amounts to around 30,000 euro. Considering the generalized economic crisis on the continent of Europe, many governments have started to show a weakness in funding and to develop alternative scenarios. The truth is that today, a series of certified national Authorities are in difficulties or unable to operate due to the economic crisis. This issue seems to have some relationship with the provision in the Communique of the Bologna Process in 2012 [Budapest] and its verification at that of Yerevan [2015] in which reference is made to the possibility of the existence of privatized Authorities as well as the possibility of the Authorities to act across a number of states on the level of the European space. 
This issue leads us however to another, hidden or silenced, advantage of the rankings. These, beyond the fact that are accepted and easily digestible by the wider public and the governments, are extremely cheap in relation to the process of quality assurance through evaluation ${ }^{8}$. If then the choice of a government is the highlighting of 'national champions', this, in combination with the high cost of the evaluations, makes the idea of the substitution of evaluation with ranking attractive. However, in this way the basic view of higher education changes from a system, whose unity and quality should be protected, to competitive educational structures whose survival may be reduced to a view that resembles social Darwinism. From here a large field of discussion opens up related to democracy as much on an institutional as on a social level.

A second but equally important stake concerns control of the mechanism, whether that is an Authority or whatever else. In the case of the national Authorities, supervision, even indirect, is to be found in the hands of the public authorities and the university communities. In contrast, most rankings are part of businesses whose target is publicity and profit, while the world of the private Authorities remains completely unchartered ${ }^{9}$. What is sure is that based on the international prices for evaluation, it seems that a vast attractive market is being shaped if one takes into account the number of higher education institutions in Europe and the world. To this we should add the three cycles of studies and the curricula offered within them, which constitute objects for potential evaluation. The number is infinite if one takes into consideration the fact that objects of evaluation could be the laboratories, internshipadministrative structures, the internationalization of the institution, etc. Finally, if to this packet we add the frequency of the need for evaluation then this new market for services looks very tempting. This unregulated chaotic new market with its huge potential profits seems [still] to scare the states, which show great reluctance in applying the provisions of the Communiques of 2012 and 2015. The relevant references in the preparatory documents for the meeting at Yerevan in May 2015 are characteristic. The position of the ENQA adds to this uncertainty: "ENQA urges all EHEA member governments to remain vigilant of the potential effects of the development of an unregulated, cross-border quality assurance services market. Related risks should be carefully analyzed and possible corrective or regulatory measures considered" [ENQA 2015].

Despite this the discussion has opened up and nobody can, at this point in time predict how it will end or which of the two approaches will predominate [evaluation or ranking], or even who will be the future bodies [public Authorities, or private initiatives], or finally what the structures [if there are any] will be in the huge new services market.

\section{BIBLIOGRAPHICAL REFERENCES}

\section{Bartzakli M. [2010]. Educational Policy and Quality Assurance in Education: Primary} Education School Advisors. Doctoral Thesis. Patra: University of Patras.

\footnotetext{
8 Here it is very interesting for one to observe that the new generation rankings, in their attempt to overcome the problems of reliability of the first attempts, develop tools with large series of variables which ultimately simulate the evaluation templates. However in this way, they seem to lose their comparative advantage: the low cost!

9 This does not mean that they are not created in a dynamic way. What is interesting is that because they cannot [yet] act easily in the European space they seem to have turned their interest to Asia and Latin America where there are no restrictions. In this way, they will quickly acquire the minimum formal qualifications (three years' experience) in order to request integration into EQAR. Germany appears to be a nursery for such private structures.
} 
ENQA. 2015. ENQA Report to Ministers Responsible for Higher Education in the EHEA. Yerevan Ministerial Conference, May 2015.

European Commission. 1991. "Memorandum on Higher Education in the European Community". COM [91] 349 final. Brussels.

HarveyL., Green D. [1993]. "Definingquality", Assessment \& Evaluationin Higher Education, 18[1]: 9-34.

Hazelkorn E. [2013]. "Rankings and Implications for Quality Assurance in Higher Education". Presentation in Institutional Evaluation Programme Annual Seminar, 26-27 September 2013. Bucharest.

[2015]. Rankings and the Reshaping of Higher Education. The Battle for World-Class Excellence. Palgrave Macmillan.

HepNet. [2013]. The Greek highereducation institutions inthe world rankings. Study 8. Patras: HepNet [http://hepnet.upatras.gr]

[2014]. The Greek highereducation institutions inthe world rankings. Study 11b. Patras: HepNet [http:// hepnet.upatras.gr]

[2016]. The Greek highereducation institutions inthe world rankings. Study 11b. Patras: HepNet [http:/ / hepnet.upatras.gr].

Institut Thomas More. [2009]. Vers quel classement européen des universités ? Étude comparative du classement de Shanghai et des autres classements internationaux. Note de Benchmarking 4. Bruxelles.

Lenzen D. [2015]. University of the world. A case for a world university system.Hamburg: Springer.

Liu N.C. and Cheng Y. [2005). "Academic Ranking of World Universities - Methodologies and Problems". Higher Educationin Europe. 30[2].

NylanderE., AmanR., HallqvistA., MalmquistA. and Sandberg Fr. [2013]. "Managing by measuring: Academic knowledge production under the ranks". Confero. 1 [1]: 5-18. doi: 10.3384/ confero.2001-4562.13v1i15

OECD. [2013a]. Assessment of Higher Education Learning Outcomes. Feasibility Study Report. Volume 2 - Data Analysis and National Experiences. Paris: OECD.

[2013b]. Assessment of Higher Education Learning Outcomes. Feasibility Study Report. Volume 3 - Further Insights. Paris: OECD.

Portelli J.P. and Vibert A.B. [2013]. "Standardization and Equity in Education". In Hare W. and Portelli J.P. [Eds.]. Philosophy of education: Introductory readings $\left[4^{\text {th }}\right.$ ed.]. Edmonton, AB: Brush Education. 
Rauhvargers A. [2011]. Global university rankings and their impact. Report. Brussels: EUA. [2013]. Global university rankings and their impact. Report II, Brussels: EUA.

Stamelos, G. [2014]. "The issue of social legitimacy of Greek universities: historical origins, future challenges [1974-present]". ACADEMIA. 4[1]: 200-236.

Tremblay K., Lalancette D. and Roseveare D. [2012]. Assessment of Higher Education Learning Outcomes [AHELO]. Feasibility Study Report Volume 1 - Design and Implementation. Paris: OECD.

Van Vught Fr.and Ziegele Fr. [eds.]. [2011]. U-Multirank: Design and Testing the Feasibility of a Multidimensional Global University Ranking. Final Report. CHERPA-Network. 